Revista Destaques Acadêmicos, Lajeado, v. 13, n. 1, 2021. ISSN 2176-3070

DOI: http://dx.doi.org/10.22410/issn.2176-3070.v13i1a2021.2544 http://www.univates.br/revistas

\title{
INCREMENTO DA PROPOSTA DE VALOR ATRAVÉS DO USO DA FERRAMENTA DE CRM NO GERENCIAMENTO DAS RELAÇÕES COM OS CLIENTES EM EMPRESAS EXPORTADORAS
}

\author{
Bruna Brancher Baron ${ }^{1}$
}

\begin{abstract}
Resumo: O presente estudo tem como objetivo identificar como é feita a incrementação da proposta de valor a partir da utilização da ferramenta de CRM em empresas exportadoras. Para tanto foi conduzido um levantamento teórico a respeito de ambos os temas, e foram observadas em 5 organizações como são percebidos o valor pelos clientes e como é gerada a relação das empresas com os clientes internacionais. Os resultados indicam que não são todas as empresas que adotam estratégias e ferramentas de gestão de relacionamento com seus clientes. Porém, todas prezam pela melhor relação com os clientes internacionais por meio de ações intrínsecas aos seus processos comerciais cotidianos. Em sua grande maioria, as respostas foram parecidas, mostrando que o bom relacionamento com os clientes e a manutenção dos mesmos - ainda que muitas vezes não se utilize o software de CRM - é sim fundamental para a incrementação da proposta de valor frente ao seu produto e/ou serviço, bem como para o sucesso de uma operação internacional.
\end{abstract}

Palavras-chave: Proposta de valor. CRM. Empresas exportadoras.

\section{INTRODUÇÃO}

A gestão de marketing contemporânea, especialmente no âmbito de empresas que operam num nível global, envolve a compreensão e entendimento do que é importante para os clientes frente à produtos e serviços que as companhias fornecem e prestam. Tendo esse tipo de informação acessível, possibilita à empresa não somente conhecer o que os clientes buscam, mas também, posicionar a marca da maneira correta de forma que seus produtos ou serviços sejam percebidos pelo público alvo, podendo desta forma, se tornar um diferencial competitivo.

1 Bacharel em Relações Internacionais UNIVATES, pós-graduanda em MBA Marketing UNIVATES. 
Diferentes são os valores percebidos pelos clientes nos produtos e serviços ofertados pelas empresas, e ter essa informação torna-se tão importante para a empresa conhecer este fator quanto fazer a gestão da sua relação com o cliente. É nesse aspecto que ganham relevância as ferramentas que possibilitam a gestão deste tipo de atividade, como o Customer Relationship Management (CRM). Esta ferramenta fica ainda mais complexa em empresas exportadoras, que precisam gerenciar clientes localizados em diferentes países com diferentes perfis de consumo e trabalho.

Visando elucidar quais são os tipos de CRM discutidos no âmbito das estratégias de marketing e como, apoiado a estes se dá incrementação da proposta de valor no gerenciamento da relação empresa $x$ clientes, o presente trabalho visa responder a seguinte questão: Como é feita a incrementação da proposta de valor a partir da ferramenta de CRM em empresas exportadoras do Rio Grande do Sul e Santa Catarina?

Para tanto, tem-se com o presente estudo o seguinte objetivo: Identificar como é feita a incrementação da proposta de valor a partir da utilização da ferramenta de CRM em empresas exportadoras. Para alcançar o objetivo proposto, busca-se identificar e analisar quais os tipos de CRM existentes, elucidar o que é a proposta de valor e identificar qual o papel do CRM na geração de uma proposta de valor capaz de manter e reter clientes.

O que impulsiona a realização deste projeto, é a busca pelo entendimento de que o processo de incrementação da proposta de valor em uma empresa pode estar ligado ao uso da ferramenta de CRM na obtenção e manutenção de clientes. A proposta de valor é construída e definida a partir da identificação e fundamentação de uma marca e/ou empresa, indicando como a mesma pode ser percebida no mercado. Assim sendo, a identificação dos elementos que diferenciam a empresa das demais, bem como quais são os benefícios específicos que ela agrega ao seu serviço para com o cliente, qual a diferenciação única que a empresa tem e faz com que os clientes a escolham ao invés do concorrente, devem ser algo que o cliente em potencial perceba prontamente de forma clara e objetiva. Desta forma, serão apresentados conceitos e definições que expliquem e exemplifiquem sobre como esta proposta de valor pode ser gerida a partir do gerenciamento da relação entre cliente e empresa e como este processo pode ou não estar relacionado ao uso do CRM.

\section{REVISÃO BIBLIOGRÁFICA}

\subsection{Proposta de Valor}

É de conhecimento que no âmbito do marketing, o valor econômico de uma empresa pode ser medido a partir do resultado da interação entre ativos tangíveis e intangíveis. Uma vez que atualmente, muito se fala em mensurar o valor das organizações a partir destes ativos é possível descrevê-los de acordo 
com as seguintes premissas: tangíveis como aqueles concretos e que podem ser tocados; intangíveis como aqueles sem substância física. Classificam-se os recursos intangíveis como: "conhecimento acadêmico dos funcionários; relacionamento com clientes, fornecedores e mercado de trabalho; e capacitação em P\&D." (KAYO ET AL., 2006).

A partir dessa colocação pode-se levar em consideração a relação entre o crescimento das empresas juntamente com tais recursos. Kayo et al., (2006) exemplificam que os ativos intangíveis são "importantes fatores de diferenciação e, dessa forma, contribuem sobremaneira para a obtenção de importantes vantagens competitivas." e isto se deve à principal característica que um ativo intangível deve ter, que é ser singular. De acordo com Barney (1991), para que uma vantagem competitiva seja sustentável, esses ativos ou recursos precisam ser valiosos, raros, inimitáveis e insubstituíveis.

Para conceituar o termo valor, é preciso entender que é possível caracterizá-lo além do âmbito financeiro, mas também - e no caso deste estudo - valor se refere à importância dada a um determinado produto, serviço ou até mesmo empresa. $\mathrm{O}$ valor pode ser entendido assim, como o benefício que tal produto ou serviço traz ao cliente. Para KOTLER (1998) o valor percebido é aquele atribuído pelos clientes ao produto ou serviço, tendo como base a relação entre os benefícios que este trará. Ainda sob esta perspectiva, GALE (1996) conceitua o valor do cliente como a qualidade percebida pelo mercado.

De encontro a este pressuposto, está o conceito de Aaker 2007 que define a proposta de valor como "é uma afirmação dos benefícios funcionais, emocionais e de auto-expressão oferecidos pela marca que proporcionam valor ao cliente". Fazendo o link com o exposto acima, onde se trata de que os ativos intangíveis preferencialmente sejam raros, é possível levantar que há uma busca por parte das empresas de se posicionarem no mercado através de algum diferencial para levarem aos clientes a ideia de que o valor pode estar atrelado primeiramente a partir da própria marca, e não somente por seus serviços e pelos seus produtos. Importante salientar também, de acordo com Torres e Alfinito 2008 que em relação aos serviços que são prometidos e prestados pelas empresas, a insatisfação do consumidor tem um impacto direto na imagem da organização, possibilitando assim, a criação de uma visão negativa desta empresa fornecedora do serviço perante seu mercado de atuação.

Para uma empresa que tenta se posicionar de uma forma no mercado, buscando levar seus clientes a serem mais propensos à um valor por ela estabelecida, Porter (1989) ressalta que em verdade são os consumidores que decidem quais aspectos valorizam em cada empresa. As organizações devem aprender sobre seus clientes, e uma vez que essa informação torna-se palpável, é nisso que devem focar seu posicionamento mercadológico. Nessa circunstância, as organizações que desenvolvem propostas de valor, percebem à sua frente possibilidades de abrir novas possibilidades na mente do consumidor em relação ao produto ou serviço ofertado. 
A proposta de valor, a partir da percepção de Webster (1994), é gerada para definir um posicionamento, e este está relacionado à proposta de valor. É o pressuposto de por qual razão os clientes optam por esta empresa e não pelo seu concorrente e é a partir desse compilado de concepções da proposta de valor percebido pelos clientes, e também pelo posicionamento das empresas, que se insere no estudo o customer relationship management - CRM.

\subsection{Customer Relationship Management}

Customer relationship management (CRM) é a combinação de pessoas, processos e tecnologia que busca entender os clientes de uma empresa (CHEN 2003). O conceito de customer relationship management não é novidade, entretanto, a utilização desta ferramenta está se tornando uma prática comum entre as empresas que estão percebendo a necessidade da manutenção de valor gerado a partir de premissas como por exemplo, a expectativa dos clientes.

O CRM caracteriza-se por ser um conjunto de processos para gerenciar a relação entre clientes, sejam eles efetivos ou potenciais, por meio do marketing (GREENBERG, 2001) e ele está presente em três segmentos:

- Operacional;

- Analítico;

- Colaborativo.

O primeiro diz respeito às funções que envolvem serviços ao cliente, no segundo segmento é onde ocorre a captação das informações dos dados do cliente, e o terceiro concerne ao centro de comunicação da rede.

Plata (2003), afirma que o CRM é "estratégia cujo propósito é transformar os processos de negócios para conservar e conseguir mais clientes". Ter em mãos uma tecnologia que analisa o comportamento do cliente, permite que as empresas identifiquem melhor os seus consumidores e foquem seus esforços de marketing nos mesmos.

Estudos como os de Morgan e Hunt (1994) e Slater e Narver (1995) demonstram que o CRM impacta positivamente na performance de uma empresa e também na performance de seus consumidores, e por essa razão, as empresas deveriam empenhar-se em desenvolver e introduzir este conceito em seu interior. Chen (2003) agrega ser mais vantajoso trabalhar na manutenção dos clientes já existentes do que ater-se apenas na busca por novos clientes, conforme aponta o trecho a seguir:

It has become well known that retaining customers is more profitable than building new relationships. Consequently, relationship marketing was developed on the basis that customers vary in their needs, preferences, buying behavior, and price sensitivity. Therefore, by understanding customer drivers and customer profitability, 
companies can better tailor their offerings to maximize the overall value of their customer portfolio (CHEN, 2003, p. 681)

A respeito da mensuração do valor, seja de uma empresa, produto ou até mesmo de um processo das empresas, pode-se dizer que apesar das perspectivas tecnológicas, as bases do CRM são relações intrínsecas entre marketing, consumidor, lucratividade, vida útil do produto e/ou serviço, retenção e satisfação que são criadas a partir do gerenciamento dos processos. Chen (2003) ainda destaca que com o avanço da internet os clientes estão cada vez mais atentos às marcas, e por isso a utilização do CRM pode trazer benefícios às empresas, uma vez que o software ajuda a focar primeiro nos clientes para construir uma relação longínqua.

Customers are more empowered today than ever before and the Internet is accelerating the trend toward greater customer empowerment. CRM applications attempt to focus on the customer first, specifically one customer at a time, to build a long-lasting mutually beneficial relationship. (CHEN, 2003, p.685).

A partir desta afirmação, vale pontuar que, no passado, os vendedores tinham conhecimento sobre seus clientes uma vez que as relações eram mais próximas e sólidas. Com a vinda da internet e o boom da informação, captar e manter os clientes está se tornando tarefa cada vez mais difícil, quando pensada nos moldes praticados anteriormente. A partir da utilização de uma ferramenta que auxilia neste processo, o CRM faz esse tipo de reaproximação com os consumidores. Ao utilizar-se do customer relationship management a organização acaba conhecendo cada um dos clientes e suas características, ajudando assim, a saber, qual tipo de produto ou serviço oferecer ao mesmo para que resulte em retenção e lealdade sobre certo (ou até mesmo longo) período de tempo.

\section{PROCEDIMENTOS METODOLÓGICOS}

Nesta seção são explicitados brevemente os procedimentos metodológicos que foram utilizados nesta pesquisa. Assim, foi considerado o método de pesquisa um "[...] conjunto de etapas, ordenadamente dispostas, a serem vencidas na investigação da verdade, no estudo de uma ciência ou para alcançar determinado fim." (GALLIANO, 1979 p.6).

Esse trabalho caracteriza-se como pesquisa qualitativa e descritiva. Para Gil (2008) a pesquisa descritiva se delimita por descrever as características de determinadas populações ou fenômenos. Uma de suas peculiaridades está na utilização de técnicas padronizadas de coleta de dados, tais como questionários e a observação sistemática. Mayring (2002) considera o estudo de caso como o primeiro ponto a ser apresentado e também o principal da pesquisa qualitativa. O estudo pode ser entendido como um mosaico, no qual, cada peça, aqui 
entendido como cada ponto estudado em particular, é relevante e vai fazer da pesquisa um todo.

Ainda, o trabalho baseia-se na revisão de literatura e análise documental com o propósito de entender como os demais autores trabalhados pensam sobre as relações entre a criação/incrementação de valor juntamente com a utilização do CRM. A coleta de dados e informações para este estudo será através da observação sistemática, a qual será feita a partir da leitura e análise de textos e documentos que trazem a conexão entre gerar, captar e sustentar a proposta de valor a partir dos recursos intangíveis resultando na retenção dos clientes a contar da incorporação do customer relationship management nas empresas.

Além disso, um roteiro de entrevistas foi construído, constituindo em 14 perguntas sobre três grandes temas que abrangem este estudo: o CRM, proposta de valor e operações internacionais de comércio exterior.

Cada pergunta foi pensada e elaborada visando elucidar e auxiliar na busca pela resposta dos objetivos propostos. Foram levantadas questões desde o conhecimento do software de CRM, se as empresas o utilizam, de que forma coletam os dados dos clientes, que outro tipo de ferramenta é utilizada para auxiliar no conhecimento e entendimento do valor dos produtos e serviços percebidos pelos clientes, etc. Para complementar essas perguntas, os temas de percepção de valor em negócios internacionais foi discutido também, procurando responder às perguntas de como é identificado o que é valor para os clientes nas empresas, como é avaliado o valor frente à produtos e serviços, como é feita a manutenção do valor gerado a partir das informações coletadas dos clientes. Além disso, qual é a posição das empresas quando o assunto é manter os clientes já existentes ou abrir novos, quais os ganhos observados no gerenciamento dos clientes e quanto do sucesso de uma operação internacional estão ligados ao bom gerenciamento do relacionamento com os clientes.

Foram contatadas 6 pessoas, de diferentes áreas: ramo alimentício, madeireiro e oleoquímicos, todas elas trabalham no setor de exportação de suas empresas, tendo contato direto com os clientes e operações internacionais, entretanto apenas 5 pessoas se disponibilizaram a responder a entrevista, conforme disposto na tabela 1. 
Tabela 1: Relação dos ramos de atuação e função dos entrevistados

\begin{tabular}{c|c|c}
\hline $\begin{array}{c}\text { Número do } \\
\text { Entrevistado }\end{array}$ & Ramo de atuação & Função desempenhada \\
\hline Entrevistado 1 & Oleoquímicos & $\begin{array}{c}\text { Analista Comercial } \\
\text { Sênior }\end{array}$ \\
\hline Entrevistado 2 & Alimentos & $\begin{array}{c}\text { Supervisora de } \\
\text { Exportação }\end{array}$ \\
\hline Entrevistado 3 & Alimentos / FMCG & Assistente de Exportação \\
\hline Entrevistado 4 & Alimentos / FMCG & Analista Comercial \\
\hline Entrevistado 5 & $\begin{array}{c}\text { Serviços especializados em } \\
\text { produtos beneficiados de } \\
\text { madeira }\end{array}$ & Gerente de Supply Chain \\
\hline
\end{tabular}

Fonte: Elaborado pelos autores.

A escolha dos entrevistados se deu a partir da premissa de trabalharem em empresas exportadoras e por tais empresas serem experientes e tradicionais neste ramo do mercado externo. Os dados foram registrados em um bloco de texto do Microsoft Word durante o período de execução das entrevistas e analisados a partir dos conceitos apresentados na revisão bibliográfica, feita para este estudo.

Dessa maneira, foram analisados os dados referentes ao uso do CRM como ator importante na verificação da manutenção de clientes a partir da criação de valor nas empresas.

\section{ANÁLISE DOS RESULTADOS}

\subsection{Customer Relationship Management}

É sabido que nos últimos anos a expansão de mídias e redes sociais fez com que empresas e marcas se conectassem ainda mais com seus clientes através desses meios. Em uma de suas obras, Kotler (2017) apresenta uma pesquisa feita pelo Internet Advertising Bureau do Reino Unido, que diz que "cerca de $90 \%$ dos consumidores de fato recomendariam as marcas depois de interagir com elas na mídia social", de uma forma que muitos desses clientes podem estar mais propensos a serem defensores da marca.

Um dos aspectos mais relevantes quando se fala sobre o processo de CRM, é o aprendizado contínuo e a criação de conhecimento a respeito dos clientes e prospects.

O entrevistado número 1 que trabalha no ramo de commodity, comenta que não há utilização de software de CRM na empresa, pois por se tratar de raw material o contato com o cliente final é quase nulo, dessa forma eles 
contatam diretamente grandes empresas do ramo e essas empresas que fazem o contato como cliente final. Os entrevistados 2 e 3 também não fazem uso de software de CRM. Já o entrevistado 5 conhece e utiliza a ferramenta de CRM, e complementa "Utilizo o Zoho, ele tem uma série de ferramentas que vai desde vendas, gerenciamento de estoque, notas, são muitas ferramentas mas só uso o CRM.".

De acordo com o entrevistado número 2, a coleta de dados dos clientes é feita no momento da negociação, onde são solicitados dados e referências comerciais para que se tenha um breve histórico deste. Ou seja, tal coleta de dados não é feita através de software de CRM. O que esta empresa utiliza são dois softwares que auxiliam na gestão desses clientes posteriormente à coleta de dados, os mesmos foram obtidos nos anos 2000 e 2014 respectivamente. Um desses softwares auxilia na confecção de documentos e também relatórios dos mais diversos tipos.

As empresas 1 e 3 fazem a coleta de dados dos clientes através de relatórios de uma plataforma online de comércio exterior, que disponibiliza as informações que a empresa procura, como por exemplo quais países tem maior demanda para cada tipo de produto, qual o volume comprado por tais países, qual o maior período de compra, etc. A partir disso é que a empresa vai avaliar quem são possíveis prospects. De acordo com os entrevistados 1 e 3 , esses relatórios são utilizados desde a abertura desta empresa e no caso do entrevistado 1, foram implementados a partir da utilização na empresa anterior a qual trabalhava.

Na empresa do entrevistado 5 , a coleta das informações é feita através de um banco de dados dentro do CRM onde ele diz que "São informações de contas das empresas, essas contas são de clientes, fornecedores, prestadores de serviço e competidores em geral. Dentro de cada uma das contas é possível encontrar dados das pessoas e seus cargos, o que fazem dentro da empresa e dados pra contato". O entrevistado comenta também que faz uso da ferramenta há quase dois anos e sua implementação foi feita a partir de pesquisa e indicações de outras empresas para fazer o uso do CRM. Quando de sua implementação, ele reitera "Foi implementado através de pesquisa de outras empresas que utilizavam ferramentas como Sales Force, um dos mais famosos, só que ele é muito caro. Então busquei uma alternativa mais simples que pudesse implementar e ser bem personalizado. Muitas coisas que não queria, eu tirava pra não poluir demais, e no primeiro mês praticamente todo dia precisava fazer ajustes. O Zoho tem essa alternativa bem legal que pode adicionar e tirar campos de registro, por exemplo posso colocar que tal fornecedor tem um certificado FSC, está habilitado pra exportar pra tal país.".

Alguns autores afirmam que muitas empresas fazem a prática do CRM naturalmente, isto é, conseguem atender às demandas de seus clientes de forma precisa preocupando-se com demais processos que não tenham influência direta do marketing. Através das primeiras perguntas da entrevista, foi possível 
constatar que somente um dos entrevistados utiliza a ferramenta de CRM e suas funções dentro do software. Entretanto, os demais entrevistados utilizam de alguma ferramenta online para coletar dados dos clientes, ou seja, por mais que não utilizem a ferramenta de CRM, eles praticam atividades que também se encontram "fora" do software, como coletar dados em outras plataformas ou ainda, durante o momento de negociação com os clientes.

\subsection{Proposta de valor}

Quando questionados sobre a proposta de valor, o entrevistado $1 \mathrm{diz}$ que não há muitas formas de agregar valor ao produto em que trabalham, justamente por se tratar de commodity e a forma de agregar valor se dá no serviço prestado. Sobre a existência de processos que identifiquem o que é valor para o cliente, o entrevistado 1 comenta "Não tem exatamente um processo porque o produto por ser commodity varia de acordo com o mercado, oferta e demanda. Atualmente por exemplo, por causa do Coronavirus o preço está subindo. É possível agregar valor fazendo algum tipo de packing diferente no produto".

Sob esta perspectiva, o entrevistado 5 complementa que em sua empresa não existe um processo de identificação de valor, entretanto é feito um exercício constante com os clientes para "reafirmar à eles a importância desse serviço que é oferecido. Constantemente tentamos reafirmar com os clientes de que esse serviço é relevante e importante, e agrega valor a sua cadeia de suprimentos, reduz custos, aumenta eficiência e traz segurança ao processo. Mas não existe nada formalizado que é uma ferramenta de geração de valor.".

Com relação a abrir novos clientes ou manter os já existentes, o entrevistado 1 comenta que por se trabalhar em um ramo onde o mercado é muito pequeno, a manutenção dos clientes já existentes é tão importante quanto abrir novos. "O objetivo da empresa é ter a o maior market share neste ramo. Na mesma linha de pensamento, o entrevistado 2 pontua "Ambos são importantes. Atualmente a empresa visa desenvolver novos clientes e novos países de atuação. A ideia é estar presente em mais países fazendo com que as vendas sejam pulverizadas e não concentradas em um determinado local. "Entretanto, visamos negócios regulares com os tradicionais clientes da mesma forma". Sob esta perspectiva, é possível analisar uma resposta complementar de ambos entrevistados 1 e 2 , na qual conseguir a maior fatia de mercado e pulverizar as vendas são objetivos iguais de empresas diferentes.

De acordo com Ronald Swift (2001), o CRM engloba a capacidade de uma organização para: descobrir clientes, manter comunicação com os clientes, assegurar que eles recebam o que desejam da organização e assegurar que esse cliente seja mantido. Como forma de manter os clientes atuais, as posição que as empresas dos entrevistados 1 e 2 preza é pelo contato direto, a cada 15 dias ou um mês, dependendo de como está a situação de compra dos clientes. Além 
disso, a participação em feiras para todos os entrevistados é muito importante para serem vistos e lembrados.

A proposta de valor é sua promessa como organização e, conforme Kotler e Keller (2006) consistem no conjunto de benefícios que a empresa promete entregar. No caso do entrevistado 2, o valor percebido pelo cliente frente à produtos e serviços é identificado através da "transparência, contato frequente, entendimento de suas necessidades, on-time delivery, produto de qualidade e seriedade para cumprir com tal", que vai de encontro à definição dos dois autores mencionados

$\mathrm{Na}$ empresa do entrevistado 5 não é feito nenhum tipo de avaliação referente ao valor frente à produtos e serviços. A empresa preza por seguir a missão, visão e valores e ele comenta que "tem essa função de tudo que [a empresa] faz, é tentar manter esse compromisso com a missão que seria impressionar os clientes e inspirar uns aos outros". Dessa maneira, mantendo o compromisso com o cliente, já é possível ter um resultado visível referente à avaliação dos serviços prestados, uma vez que se o serviço não é feito da melhor maneira possível, a resposta do cliente também não será satisfatória.

\subsection{Manutenção e gerenciamento dos clientes}

Para o entrevistado 1, o sucesso de uma operação internacional está atrelado ao bom relacionamento com os clientes. Por se tratar de um mercado distinto, porém com diversos fornecedores do mesmo produto, "nem sempre o preço mais baixo do concorrente será suficiente pra que o cliente compre dele. Ter um bom relacionamento faz com que a parceria entre cliente $\mathrm{x}$ fornecedor prevaleça.".

A necessidade de mais ferramentas para auxiliar no relacionamento com os clientes foi levantada pelo entrevistado 2 como por exemplo fazer mais uso das redes sociais, SAC e mailing do departamento de marketing. Foi aplicada recentemente uma pesquisa de satisfação com os clientes, e o resultado foi que o posicionamento dos clientes está em relação à produto $x$ atendimento. Neste caso, a visão da empresa pós-resultado desta pesquisa é de "proporcionar ao cliente uma experiência entre produto + pré-venda + pós venda", tornando esse tipo de atendimento como diferencial que os clientes buscam, tanto nos momentos de satisfação como quando precisam solucionar algum problema que possa vir a ocorrer.

A partir da visão do entrevistado 2 com relação ao foco no cliente, é possível fazer a ligação com a citação de Kotler sobre o chamado CRM social onde cita que "é uma grande mudança em relação ao CRM tradicional. Enquanto a tradicional gestão do relacionamento com o cliente é tipicamente voltada para empresas, o CRM social é voltado para o cliente." (KOTLER, 2017, p.188). Importante ressaltar também, que a busca por minimizar as perdas através do suporte ao cliente é relevante nessa ótica. 
Como comentado anteriormente, o valor também pode ser mensurado a partir de ativos intangíveis, ou seja, a partir do quanto uma pessoa da organização pode contribuir intelectualmente para a mesma. Esses recursos humanos criam valor para os investidores, os empregados e demais stakeholders, quando eles têm o entendimento da proposta de valor da organização. Proposta de valor é, no entendimento de Kotler e Pfoertsch (2008), mais do que o posicionamento central da oferta. De acordo com esses conceitos, é possível encaixar o que para o entrevistado 5 amplia a proposta de valor a partir do relacionamento com os clientes. O entrevistado diz que "como a gente trabalha com cotação de venda, tentamos agir pro ativamente, tentando criar um perfil dos hábitos de compra dos clientes. Quando conseguimos fechar o negócio e está dando certo, tentamos fazer um link do fornecedor diretamente com o cliente." dessa forma, cria-se um vínculo com o cliente a partir da satisfação gerada nesse tipo de serviço e suporte dado pela empresa. Pode-se dizer assim, que os ativos intangíveis, ou seja, o conhecimento técnico e a bagagem que o entrevistado 5 tem, são de extrema importância para que a geração de valor e a manutenção da mesma com seus clientes seja efetiva.

A manutenção do valor gerado a partir das informações coletadas dos clientes na empresa do entrevistado 2 é feita através de análises de um dos softwares utilizados. São verificados volumes e sazonalidades por mercado, e através desses dados é possível identificar e entender o cenário de cada cliente em determinado momento, dessa forma a empresa mantém o contato para que o negócio siga fluindo, e não manter apenas negócios "spot". Os entrevistados 3 e 4 ainda complementam que o valor gerado com as informações fornecidas pelo cliente vão muito além de networking, "manter o bom relacionamento permite troca e intermédio de novas parcerias.".

Para os entrevistados 1 e 2, abrir novos clientes e manter os já existentes são simultaneamente importantes. No cenário atual, o que ambas empresas buscam é desenvolver novos clientes - e pra isso a participação em feiras é muito importante - e novos países de atuação, como forma de pulverizar os produtos e serviços, e não estando presente somente em um determinado local. No entanto, a manutenção dos clientes tradicionais também é feita para manter os negócios regulares. Essa manutenção é feita por contato semanal, atendendo às demandas e negociações em andamento. Com os relatórios disponibilizados pelo software, a empresa 2 consegue averiguar seus clientes e por qual motivo compraram ou deixaram de comprar nos últimos meses, e a partir disso contatar os mesmos. Para o entrevistado 1 e 4 este contato constante é primordial para o andamento do negócio.

Na empresa do entrevistado 5, mais prioritário do que a manutenção dos clientes já existentes, é fazer com que o negócio deles cresça. Abrir novos clientes é importante também, porém como a empresa raramente trabalha com vendas spot, e atuando num ramo muito novo no Brasil, o relacionamento com 
os clientes é de suma importância. Em resumo, o entrevistado 5 só vê ganhos na manutenção dos clientes.

A partir da manutenção dos clientes, o entrevistado 2 comenta que um dos ganhos que se tem fazendo isso é a regularidade na compra, parceria em momentos de crise e transparência ao receber informações do mercado pois há relação de confiança entre cliente $x$ empresa. Além disso, muitas vezes com o auxílio por parte destes clientes é possível fazer inserção de um novo produto no mercado, ter maior entendimento da forma com o produto é comercializado localmente, compreender quais ações de marketing possam auxiliar no aumento das vendas, etc. Manter os preços negociados ao longo do tempo também gera tranquilidade na compra de insumos, por conta da regularidade mantida pelos clientes, pois para o entrevistado 2, a "relação de parceria é ganha-ganha na qual, ambos buscam o mesmo objetivo". Já para o entrevistado 5, o qual é importante ressaltar que exporta serviços, a manutenção do relacionamento deve ser feita em duas direções: com os clientes e também com os fornecedores.

No caso dos fornecedores contato com cada um deve ser no mínimo semanal, para manter-se atualizado nas condições e capacidades de cada um, para então achar a forma mais competitiva para passar aos clientes. Já com estes, são feitas visitas semestrais, pois a maioria dos clientes se encontra nos Estados Unidos, e também participação de feiras anuais do ramo. Todas essas ações do entrevistado 5 são registradas no CRM, que acabam por auxiliar na organização dos dados de cada fornecedor e cliente.

O sucesso de uma operação internacional para o entrevistado 2 está suportado na ideia de que quando existem várias marcas de um mesmo tipo de produto, talvez o relacionamento não faça tanta diferença, pois o produto é parecido e conhecido como os demais no mercado. Em grandes empresas o cliente pode ser considerado somente mais um para somar na carteira, porém, o bom relacionamento é a base do sucesso nas operações internacionais da empresa 2. Atender a todos os clientes da melhor forma possível, entender suas necessidades, ser solícito e demonstrar interesse pelo que ele menciona faz com que se sintam importantes e especiais, resultando na confiança desse negócio. Da mesma forma, analisando a resposta do entrevistado 5, a manutenção do relacionamento com os clientes é fundamental, pois utilizando as informações que constam no CRM a partir de negócios feitos anteriormente, é possível obter informações fora do universo dos negócios, como detalhes pessoais dos clientes que podem servir como um "quebra-gelo" pra uma próxima ligação ou visita. Ter esse tipo de relacionamento contribui para a construção do relacionamento e ainda mais, na manutenção deste. Praticamente em todos os casos, os entrevistados demonstram que há ganhamos em ter um bom relacionamento com os clientes, mesmo que em algumas vezes não é somente $o$ relacionamento que conta na soma final, mas outras variáveis também, como a oferta e demanda, preços e sazonalidade. 
O sucesso de uma operação internacional, para o entrevistado 5, está $100 \%$ atrelado a um bom relacionamento com os clientes. Como exportador de serviços, o entrevistado comenta que "querendo ou não, sou bastante substituível, então meu produto é o relacionamento com o cliente. Se eu não tenho isso com eles [os clientes], então não tenho mais nada, tudo que tenho pra oferecer é ser técnico e especializado, só que se não tenho relacionamento e vínculo com os clientes, não tenho sucesso no meu negócio.".

Para finalizar a análise dos dados, fica a reflexão feita pelo entrevistado 5 com relação ao uso do CRM como ferramenta de geração e manutenção do valor com os cliente "A maior dificuldade de usar a ferramenta é achar que da mais trabalho que resultado. Se investe nisso, dá resultado sim".

\section{CONCLUSÃO}

A partir dos dados coletados durante as entrevistas feitas para este estudo, pôde-se perceber que $60 \%$ dos entrevistados conhecem as ferramentas de CRM, porém, nem todos sabem de suas funcionalidades e resultados que se pode obter. Somente $40 \%$ dos entrevistados não conhecem o software de CRM, porém, praticam o mesmo indiretamente de outras formas. Em sua grande maioria, as respostas foram parecidas, mostrando que o bom relacionamento com os clientes e a manutenção dos mesmos - ainda que muitas vezes não se utilize o software de CRM - é sim fundamental para a incrementação da proposta de valor frente ao seu produto e/ou serviço, bem como para o sucesso de uma operação internacional.

Com apenas um dos entrevistados utilizando a ferramenta para auxílio na identificação, retenção e manutenção dos clientes, pôde-se identificar que a incrementação da proposta de valor a partir do software, é sim um ganho percebido pela empresa. Todo o trabalho feito com os clientes, tendo auxílio do CRM faz com que a criação de um vínculo entre empresa $x$ cliente seja de certa maneira mais possível e acessível do que sem a utilização deste. Ressaltase também que a criação desse vínculo pode ser feita de outras formas que não apenas utilizando do CRM, como mostrado pelas demais empresas entrevistadas, entretanto, tende a ser um processo (algumas vezes) mais custoso e demorado.

Como já exposto, nem todas as empresas utilizam do software para auxílio da identificação de clientes, entretanto, constata-se também que a maioria das empresas pratica o customer relationship management de forma natural através de outros meios como planilhas para acompanhamento, tendo um cuidado semanal ou quinzenal de contato através de follow up dos assuntos pendentes com os clientes como também participando de eventos e feiras do ramo. A prática do CRM sem o software tende a demonstrar resultados mais lentos e de forma gradual, pois utilizando-se de ferramentas habituais como Microsoft Excel, e-mail e até redes sociais, a incrementação do valor do 
produto ou serviço da empresa também poderá ocorrer na mesma proporção e velocidade uma vez que levará mais tempo para saber o que o cliente busca de benefícios em seu produto/serviço.

O conceito de customer relationship management ainda não é explorado a fundo pelos empresários, fazendo com que de certa maneira, a empresa não tenha conhecimento real de quem são seus clientes, por que não conseguem reter os clientes já existentes, dentre outros questionamentos que possam surgir.

A pesquisa foi conduzida com 5 pessoas, o que não representa uma realidade universal, e sim, a realidade de cada um dos casos observados. Como fator limitador da pesquisa, é possível pontuar que poucos entrevistados conheciam a ferramenta de CRM, fazendo com que o resultado da pesquisa não se concretizasse da forma esperada. Por outro lado, ao fazer a pesquisa com essas empresas, foi possível apresenta-los ao tema do CRM, e quem sabe assim tornar este assunto mais conhecido e difundido.

Tal pesquisa poderia ser replicada em novas realidades, para identificar padrões de comportamento e também para compreender melhor o comportamento dos clientes perante outros produtos e serviços. Recomendase para estudos futuros uma nova interação com os casos observados a fim de identificar que novas práticas foram adotadas depois do primeiro contato com o CRM.

\section{REFERÊNCIAS}

AAKER, David A.. Construindo marcas fortes. Porto Alegre: Bookman, 2007.

Barney, J. (1991, March). Firm resources and sustained competitive advantage. Journal of Management, 17(1), 99-120.

Becker, J. U., Greve, G., \& Albers, S. (2009). The impact of technological and organizational implementation of CRM on customer acquisition, maintenance, and retention. International Journal of Research in Marketing, 26(3), 207-215.doi:10.1016/j. ijresmar.2009.03.006

Chen, I. J., \& Popovich, K. (2003). Understanding customer relationship management (CRM). Business Process Management Journal, 9(5), 672-688. doi:10.1108/14637150310496758

GALE, Bradley T. Gerenciando o valor do cliente: criando qualidade e serviços que os clientes podem ver. São Paulo: Pioneira, 1996.

GALLIANO, A. Guilherme. O método científico: teoria e prática. São Paulo: Harbra, 1986.

GIL, Antonio Carlos. Como elaborar projetos de pesquisa. 4. ed. São Paulo: Atlas, 2008. 
GLENN ROWE, W.. Liderança estratégica e criação de valor. Revista de Administração de Empresas, 42(1), 1-19, 2002. doi:10.1590/s0034-75902002000100003

KAYO, E. K., KIMURA, H., MARTIN, D. M. L., \& NAKAMURA, W. T. Ativos intangíveis, ciclo de vida e criação de valor. Revista de Administração Contemporânea, 10(3), 73-90, 2006. doi:10.1590/s1415-65552006000300005

KOTLER, Philip. Administração de marketing: análise, planejamento, implementação e controle. São Paulo: Atlas, 1998

KOTLER, Philip; PFOERTSCH, Waldemar. Gestão de marcas em mercados B2B. Porto Alegre: Bookman, 2008.

KOTLER, Philip e KELLER, Kevin L. Administração de marketing. São Paulo: Pearson Prentice Hall, 2006.

KOTLER, Philip, HERMAWAN, Kartajaya e IWAN, Setiawan. Marketing 4.0 do tradicional ao digital. Rio de Janeiro: Sextante, 2017.

MAYRING, Ph. Einführung in die qualitative Sozialforschung [Introdução à pesquisa social qualitativa]. 5. ed. Weinheim: Beltz, 2002

PLATA, Sandra. De acordo com a vontade do cliente. Disponível em: http:/ /www. intermanagers.com.br/archivo/nota.jsp?id=707.

PORTER, Michael E. Vantagem competitiva. Rio de Janeiro: Campus, 1989.

SCHARF, Edson Roberto. PROPOSTA DE VALOR NA CONSTRUÇÃO DA IDENTIDADE DE MARCA: O CAPITAL HUMANO ENVOLVIDO NA ÁREA MERCADOLÓGICA. 341 p. Tese. Universidade Federal de Santa Catarina. 2009.

SWIFT, Ronald. CRM, customer relationship management: o revolucionário marketing de relacionamento com os clientes. Rio de Janeiro: Elsevier, 2001.

TORRES, Cláudio V. e ALFINITO, Solange. Cultura e o comportamento do consumidor: os valores culturais são preditores do consumo? In: TEIXEIRA, Maria L. M. (org.). Valores humanos e gestão: novas perspectivas. Cap. 5, p. 117-141. São Paulo: Editora Senac, 2008.

WEBSTER, Jr., Frederick E.. Marketing-driven management. New York: John Wiley \& Sons, 1994. 